\title{
Metastatic colorectal cancer: treatment with panitumumab
}

\author{
Author: Brazilian Medical Association \\ Participants: Antonio Silvinato; Isabela da Silveira Pedreira; \\ João Conrado Bueno dos Reis; João Guilherme Zétula Marcondes; Wanderley M Bernardo' (iD)
}

Final version: October 22, 2016

1. Brazilian Medical Association, São Paulo, SP, Brasil

The Guidelines Project, an initiative of the Brazilian Medical Association, aims to combine information from the medical field in order to standardize producers to assist the reasoning and decision-making of doctors.

The information provided through this project must be assessed and criticized by the physician responsible for the conduct that will be adopted, depending on the conditions and the clinical status of each patient.

\section{METHOD OF EVIDENCE COLLECTION}

This guideline followed the standard of a systematic review with evidence recovery based on the Evidence-Based Medicine movement, where clinical experience is integrated with the ability to critically analyse and rationally apply scientific information, thus improving the quality of medical care. MBE uses existing and currently available scientific evidence with good internal and external validity for the application of its results in clinical practice., ${ }^{1,2}$

Systematic reviews are currently considered the level I of evidence for any clinical issue since they systematically summarize information on a particular topic through primary studies (clinical trials, cohort studies, case-control or cross-sectional studies) using a reproducible methodology, in addition to integrating information on effectiveness, efficiency, efficacy and safety.,

We used the structured way of formulating the question synthesized by the acronym P.I.C.O., where the $\mathbf{P}$ corresponds to the patient with Metastatic Colorectal Cancer, I for intervention with Chemotherapy with panitumumab, $\mathrm{C}$ for comparison of Chemotherapy without panitumumab and placebo, and $\boldsymbol{O}$ for outcome of survival and adverse events. From the structured question, we have identified the descriptors that were the basis of the search for evidence in the databases Medline-PubMed (595 papers) and COCHRANE/Lilacs/BVS (210 papers). Thus, after the eligibility criteria (inclusion and exclusion), 12 papers were selected to answer the clinical questions (Annex I).

\section{CLINICAL QUESTIONS:}

Do patients with metastatic colorectal cancer benefit from the use of panitumumab?

Degree of recommendation and strength of evidence

A: Experimental or observational studies with better consistency.

B: Experimental or observational studies with less consistency.

C: Case reports / uncontrolled studies.

D: Opinion with no critical assessment, based on consensus, physiological studies or animal models.

\section{Purpose}

The purpose of this guideline is to identify the best evidence currently available regarding the use of panitumumab in patients with metastatic colorectal cancer.

\section{Conflict of interest}

No conflict of interest was declared by participants in the preparation of this guideline. 


\section{INTRODUCTION}

Panitumumab is a fully human recombinant monoclonal IgG2 antibody that binds with high affinity and epithelial growth factor receptor (EGFR) specificity. EGFR is a transmembrane glycoprotein which is a member of a type I receptor tyrosine kinase subfamily including EGFR (HER1/c-ErbB-1), HER2, HER3 and HER4 ${ }^{3}$. EGFR promotes cell growth in normal epithelial tissues including skin and hair follicle, and expresses itself in a variety of tumour cells ${ }^{4}$.

Panitumumab binds to the binding domain of the EGFR ligand and inhibits the receptor autophosphorylation induced by all known EGFR ligands. This binding results in receptor internalization, inhibition of cell growth, induction of apoptosis and decreased production of interleukin 8 and vascular endothelial growth factor ${ }^{5,6}$.

\section{RESULTS OF SELECTED EVIDENCES}

\section{Monotherapy - Second or third-line}

The results of a multicentre, international (Western Europe, Central Europe, Eastern Europe, Canada, Australia, New Zealand), open-label phase III Randomized Controlled Trial (RCT) in which 463 patients with metastatic colorectal cancer with EGFR expression were randomized to receive panitumumab (6 $\mathrm{mg} / \mathrm{kg}$ per IV infusion over 60 minutes every 2 weeks until disease progression or unacceptable toxicity) and "best supportive care" (BSC) [n = 231] or "better supportive care alone" [ $\mathrm{n}=232]$. The study was reported in a major publication ${ }^{7}(\mathbf{B})$ and five complementary publications $\mathbf{8}^{\mathbf{8}, \mathbf{1 0}, 11,12}$ which are summarized in Table 1. The eligibility criteria included pathological diagnosis of metastatic colorectal adenocarcinoma and radiological documentation of disease progression during treatment or within 6 months after the last administration of fluoropyrimidines, irinotecan and oxaliplatin (second or third-line).
In the BSC group, $176(76 \%)$ of the patients received panitumumab (PAN) according to a crossover protocol. The average crossover time was 7 weeks (6.6 - 7.3 weeks) and the average follow-up after the crossover was 61 weeks (18 - 103 weeks). ${ }^{7}(\mathbf{B})$

The median overall survival (OS) values were not given, however, it was reported that there was no difference with statistical significance between groups in the OS analysis (hazard ratio $[\mathrm{HR}]=1.00,95 \% \mathrm{CI}$ $0.82-1.22, \mathrm{p}=0.81)$. This result may have been affected by the high crossover rate. ${ }^{8}(\mathbf{B})$

A retrospective evaluation of the panitumumab efficacy and KRAS status (wild-type [WT] and mutant) showed no statistically significant difference in OS between the treatment groups in either KRAS status. ${ }^{10}$ (B) HRs for OS were 1.02 (95\% CI 0.75-1.39) and 0.99 (95\% CI 0.75 of 1.29) for the mutant KRAS and KRAS-WT respectively ${ }^{10}(\mathbf{B})$. There was also no difference in median OS. Patients with KRAS-WT treated with panitumumab showed a median OS of 8.1 months compared to 7.6 for those treated with BSC; and patients with mutant KRAS treated with panitumumab showed a median OS of 4.9 months, compared with 4.4 months for those treated with $\operatorname{BSC}^{10}(\mathbf{B})$.

An improvement in progression-free survival (PFS) was observed in the group of patients treated with PAN + BSC $(\mathrm{HR}=0.54,95 \% \mathrm{CI}, 0.44-0.66 ;[\mathrm{P}<$ 0.0001]). The difference between the groups was 5 days for the median PFS (56; 95\% CI 55 - 59 vs. 51; 95\% CI 50 - 54) and 37 days for the average PFS (average [SD]; 96.4 [5.3] vs. 59.7 [3.75]), favourable to PAN + BSC. $^{7,13}(\mathbf{B})$

A supplemental analysis for KRAS gene revealed the benefit of panitumumab + BSC in patients with KRAS-WT (non-mutant) codons 12 and 13 (HR = 0.45, $95 \%$ CI 0.3 - 0.59), with an increase of 5 weeks in the median PFS (12.3 vs. 7.3). There was no difference in the PFS between treatments in patients with mu-

TABLE 1 - SUMMARY OF MAIN AND COMPLEMENTARY STUDY FOR PANITUMUMAB + BSC VS BSC IN MCRC

\begin{tabular}{|c|c|c|}
\hline Study & Description & $\begin{array}{l}\text { Average follow-up (interval) } \\
\text { (months) }\end{array}$ \\
\hline Van Cutsem et al ${ }^{7}$ & PAN + BSC vs BSC main study & $8,8(3,8-19)$ \\
\hline Siena et $\left.a\right|^{8}$ & Analysis of PFS association with symptoms of colorectal cancer, HRQoL and OS & $18(13-28.3)$ \\
\hline Van Cutsem et al ${ }^{9}$ & Crossover Extension Study & $15.3(4.5-25,8)$ \\
\hline Amado et $\left.a\right|^{10}$ & Retrospective analysis of the main study for KRAS & $\begin{array}{l}14,1 \text { (for } 36 \text { patients remaining } \\
\text { at the time of analysis) }\end{array}$ \\
\hline Peeters et al'11 & Analysis of the association of skin toxicity severity with PAN efficacy & $18(13-28,3)$ \\
\hline Peeters et al ${ }^{12}$ & Retrospective analysis of the main study for various genes & - \\
\hline
\end{tabular}

BSC, best supportive care; PAN, panitumumab; OS, overall survival; PFS, progression-free survival; HRQoL, health-related quality of life. 
tations at codons 12 and 13 of the KRAS gene (HR = $0.99 ; 95 \%$ CI $0.73-1.36) .{ }^{10}(\mathbf{B})$

With this same study, in a retrospective analysis involving 90\% $(n=288)$ of the tumour samples that were available (PAN, $\mathrm{n}=147$; BSC, $\mathrm{n}=141$ ), information was obtained for several genes. Mutation rates for KRAS, NRAS and BRAF were $45 \%, 5 \%$ and $7 \%$, respectively. PAN treatment was associated with higher PFS among patients with KRAS-WT (codons 12/13/61); HR = 0.39 (95\% CI 0.28 - 0.56). Among patients with KRAS-WT (codons 12/13/61), treatment with panitumumab showed benefits, increasing PFS in patients who also had NRAS-WT (no mutation; $\mathrm{n}$ $=138)$, [HR $=0.39 ; 95 \%$ CI $0.27-0.56 ; p<0.001]$ or BRAF-WT $(\mathrm{n}=115)$, [HR = 0.37; 95\% CI 0.24 - 0.55; $\mathrm{p}$ $<0.001]$. However, there was no such benefit when patients had a mutation in NRAS ( $\mathrm{HR}=1.94,95 \% \mathrm{CI}$ $0.444-8.44) . .^{12}(\mathbf{B})$.

The most common adverse event associated with panitumumab was skin toxicity $(90 \%$ in the PAN group and $9 \%$ in the BSC), although it has been shown that the severity of skin toxicity may be associated with efficacy ${ }^{11}(\mathbf{B})$. Grade 3 or 4 hypomagnesemia occurred in $3 \%$ of patients in the PAN group.

The single arm extension study showed that $92 \%$ of the patients had adverse events related to panitumumab (16\% had grade 3 and $2 \%$ had grade 4 acute renal failure, pulmonary embolism). ${ }^{9}(\mathbf{B})$

\section{FIRST-LINE}

In a multicentre, open-label, phase III trial that included patients with previously untreated metastatic colorectal cancer (mCRC) and Eastern Cooperative Oncology Group (ECOG) performance status from 0 to 2. Patients $(\mathrm{N}=1,183)$ were randomized to FOLFOX-4 plus panitumumab $6 \mathrm{mg} / \mathrm{kg}$ IV for 1 hour, every 2 weeks on day 1 (D1) versus FOLFOX-4 alone. FOLFOX-4 was administered every 2 weeks and consisted of oxaliplatin $85 \mathrm{mg} / \mathrm{m}^{2}$ IV infusion on D1 + leucovorin $200 \mathrm{mg} / \mathrm{m}^{2}$ (or equivalent) IV infusion D1 and D2 + fluorouracil $400 \mathrm{mg} / \mathrm{m}^{2}$ (bolus) + fluorouracil $600 \mathrm{mg} / \mathrm{m}^{2}$ (continuous infusion of 22 hours) D1 and D2. KRAS status results were present for $93 \%$ of the patients (central and blind laboratory). ${ }^{14}(\mathbf{B})$

In patients with mCRC and KRAS-WT (605 patients) an improvement with statistical significance was observed in PFS with FOLOFOX-4 + PAN compared to FOLFOX-4 (HR $=0.80,95 \%$ CI 0.66 to $0.97 ; p=$ 0.02). There was an increase of 1.6 months in the me- dian PFS (9.6 months [95\% CI 9.2 to 11.1] for FOLFOX-4 + PAN vs 8.0 months [95\% CI 7.5 to 9.3] for FOLFOX-4). There was no improvement in OS for these patients $(\mathrm{HR}=0.83,95 \% \mathrm{CI} 0.67$ to $1.02, \mathrm{p}=0.072){ }^{14}(\mathbf{B})$

In patients with exon 2 mutant KRAS (40\% of patients), there was a statistically significant reduction in PFS with FOLFOX-4 + PAN compared to FOLFOX-4 $(\mathrm{HR}=1.29,95 \% \mathrm{CI} 1.04$ to $1.62 ; \mathrm{p}=0.02)$. There was no statistically significant reduction in OS; $(\mathrm{HR}=$ 1.24, 95\% CI 0.98 to 1.57). The median PFS was 7.3 months (95\% CI 6.3-8.0) for FOLFOX-4 + PAN and 8.8 months (95\% CI 7.7 - 9.4) for FOLFOX-4.

Subsequently, a retrospective analysis of a predefined subset of data from this study ${ }^{15}(\mathbf{B})$ evaluated 108 (17\%) patients with no mutation in KRAS exon 2 but with additional RAS mutations (KRAS exon 3 or 4, NRAS exon 2,3 , or 4$)$ and $53(8 \%)$ patients with BRAF exon 15 mutation. Patients without any RAS or BRAF mutations had a median PFS greater $(10.8$ months [95\% CI 9.4-12.4] versus 9.2 months [95\% CI 7.4 - 9.6] when treated with FOLFOX-4 + PAN and compared with FOLFOX-4 alone, therefore, an increase of 1.4 months in the median PFS.

The most common grade 3 and 4 adverse events known to be associated with anti-EGFR therapy were neutropenia, skin toxicity, diarrhoea, and neurological toxicity.

\section{SECOND-LINE}

Patients with mCRC without prior therapy with Anti-EGFR and ECOG performance status from 0 to 2. Patients $(\mathrm{N}=1,186)$ who had not responded to a prior chemotherapeutic treatment (fluoropyrimidine scheme) were randomized to panitumumab $6 \mathrm{mg} / \mathrm{kg}$ every two weeks plus FOLFIRI or FOLFIRI alone, until disease progression or intolerability. FOLFIRI consisted of irinotecan $180 \mathrm{mg} / \mathrm{m}^{2}$ and racemic leucovorin $400 \mathrm{mg} / \mathrm{m}^{2}$ (or L-leucovorin $200 \mathrm{mg} / \mathrm{m}^{2}$ ) by IV infusion on D1 and 5-fluorouracil (5-FU) $400 \mathrm{mg} / \mathrm{m}^{2}$ bolus on D1, followed by 5 -FU $2,400 \mathrm{mg} / \mathrm{m}^{2}$ administered in continuous infusion over D1 and D2. The KRAS status was available for $91 \%$ (55\% KRAS-WT and $45 \%$ mutant KRAS) of patients. The average follow-up was 10.213.3 months for patients with KRAS-WT. ${ }^{16}(\mathbf{B})$

When associated with the FOLFIRI regimen as a second-line treatment, patients with KRAS-WT who received panitumumab showed a 2-month increase in median PFS (5.9 months [95\% CI, 5.5-6.7] versus 3.9 months [95\% CI, 3.7-5.3], $\mathrm{p}=0.004)$. The increase 
in median OS of 2 months was not statistically significant (14.5 months versus 12.5 months, $p=0.12) .{ }^{16}(\mathbf{B})$

Patients with mutant KRAS did not present differences with statistical significance in PFS and OS evaluations. ${ }^{16}(\mathbf{B})$

This same study in a 64-week average follow-up analysis ${ }^{17}(\mathbf{B})$ for KRAS-WT patients showed similar results. Comparing the addition of panitumumab to FOLFIRI with FOLFIRI alone, there was an increase of 1.8 months in the median PFS ( $p=0.023)$, but the 2 month increase in the median OS did not present statistical significance $(\mathrm{p}>0.05) .{ }^{17}(\mathbf{B})$

The most common grade 3 and 4 adverse events were skin toxicity, neutropenia and diarrhea. ${ }^{17}(\mathbf{B})$

\section{PANITUMUMAB + BEVACIZUMAB}

Multicentre open-label RCT that evaluated panitumumab added to bevacizumab associated with chemotherapy based on oxaliplatin and irinotecan as the first-line in non-selected mCRC patients with KRAS mutation. Panitumumab was discontinued after planned interim analysis showed that when it was added to the FOLFOX/bevacizumab regimen, there was a worsening in PFS and increased toxicity compared to the FOLFOX/bevacizumab regimen alone. In both chemotherapy regimens (oxaliplatin and irinotecan), panitumumab was associated with a higher rate of disease progression or death $(\mathrm{NNH}=$ 16) and overall mortality ( $\mathrm{NNH}=11$ in oxaliplatin and $\mathrm{NNH}=14$ in irinotecan). ${ }^{18}(\mathbf{B})$

\section{RECOMMENDATIONS}

1. $P A N+B S C$ versus $B S C$ (second or thirdline monotherapy)

Patients with mCRC with EGFR expression, after confirmation of failure of regimens containing fluoropyrimidine, oxaliplatin and irinotecan.

- There was no statistically significant difference between groups in the analysis of overall survival (HR $=1.00,95 \%$ CI $0.82-1.22 ; \mathrm{p}=0.81)$.

- Panitumumab showed no statistically significant difference in overall survival (OS) between the treatment groups in any of the KRAS (wildtype or mutant) status.

- There was no difference in PFS between treatments in patients with mutations at codons 12 and 13 of the KRAS gene (HR $=0.99 ; 95 \%$ CI 0.73 $-1.36)$.
- The difference between groups was 5 days for the median PFS (56 vs 51) and 37 days for the average PFS (average [SD], 96.4 [5.3] vs 59.7 [3.75]), favourable to PAN + BSC.

- There was benefit of panitumumab + BSC in patients with KRAS-WT (non-mutant) codons 12 and 13 (HR $=0.45$, 95\% CI $0.3-0.59$ ), with an increase of 5 weeks in the median PFS (12.3 vs 7.3).

- In patients with KRAS-WT (codons 12/13/61), treatment with panitumumab showed benefit, increasing PFS in patients who also had NRASWT (no mutation), [HR $=0.39 ; 95 \%$ CI 0.27 $0.56 ; \mathrm{p}<0.001$ ] or BRAF-WT, [HR $=0.37 ; 95 \% \mathrm{CI}$ 0.24 - $0.55 ; \mathrm{p}<0.001]$.

- In patients with KRAS-WT (codons 12/13/61), treatment with panitumumab showed no benefit when patients had a mutation in NRAS (HR = $1.94,95 \%$ CI, 0.444-8.44)

\section{FOLFOX-4 + PAN versus FOLFOX-4 -}

\section{First-line}

Patients with mCRC untreated for metastatic disease and KRAS-WT:

- There was no increase in $\mathrm{OS} ;(\mathrm{HR}=0.83,95 \% \mathrm{CI}$ 0.67 to 1.02 ).

- There was a statistically significant increase in PFS with FOLOFOX-4 + PAN compared to FOLFOX-4 (HR = 0.80, 95\% CI 0.66 to 0.97; $p=0.02)$.

- There was an increase of 1.6 months in the median PFS (9.6 vs 8.0 months).

- Patients with mRCA and KRAS exon 2 mutant

- There was no difference in OS; (HR = 1.24, 95\% CI 0.98 to 1.57 ).

- In patients with KRAS exon 2 mutant there was a reduction in PFS with FOLFOX-4 + PAN compared to FOLFOX-4; (HR $=1.29,95 \%$ CI 1.04 to $1.62 ; \mathrm{p}=0.02$ ).

- Patients without any RAS mutations (KRAS exon 2, 3 or 4; NRAS exon 2, 3, or 4) or BRAF exon 15 mutation showed an increase of 1.4 months in the median PFS (10.8 months [95\% CI 9.4-12.4] versus 9.2 months [95\% CI 7.4-9.6] when treated with FOLFOX-4 + PAN and compared to FOLFOX-4.

\section{FOLFIRI + PAN versus FOLFIRI - Second-line}

Patients with mCRC who had previously received a fluoropyrimidine chemotherapeutic regimen.

Patients with KRAS-WT:

- The increase in OS median of 2 months was not 
statistically significant (14.5 months versus 12.5 months; $\mathrm{p}=0.12$ ).

- Patients receiving panitumumab showed a 2-month increase in median PFS (5.9 months versus 3.9 months; $p=0.004$ ).

- Patients with mutant KRAS

- There was no difference in PFS and OS assessments (without statistical significance)

\section{PAN + QT based on Oxaliplatin/} bevacizumab or QT based on irinotecan/ bevacizumab versus QT Oxal/bevacizumab or QT Iri/bevacizumab

- In both chemotherapy regimens (oxaliplatin and irinotecan), panitumumab was associated with a higher rate of disease progression or death $(\mathrm{NNH}=16)$ and overall mortality $(\mathrm{NNH}=$ 11 in oxaliplatin and $\mathrm{NNH}=14$ in irinotecan).

- The most common adverse events related to the use of panitumumab, grade 3 and 4 were skin toxicity, neutropenia, diarrhoea, pulmonary

\section{REFERENCES}

1. Nobre MR, Bernardo WM, Jatene FB. A prática clínica baseada em evidencias. Parte I - Questões clínicas bem construídas. Rev Assoc Med Bras 2003; 49(4):445-9.

2. Bernardo WM, Nobre MR, Jatene FB. A prática clínica baseada em evidencias. Parte II - Questões clínicas bem construídas. Rev Assoc Med Bras 2004; 50(1):104-8.

3. Herbst RS. Review of epidermal growth factor receptor biology. Int | Radiat Oncol Biol Phys 2004;59(2 Suppl):21-6. Review. PMID: 15142631.

4. Holbro T, Hynes NE. ErbB receptors: Directing key signaling networks throughout life. Annu Rev Pharmacol Toxicol 2004;44:195-217.

5. Wainberg Z, Hecht JR. Panitumumab in colon cancer: A review and summary of ongoing trials. Expert Opin Biol Ther 2006;6:1229 -1235.

6. Veronese ML, O'Dwyer PJ. Monoclonal antibodies in the treatment of colorectal cancer. Eur | Cancer 2004;40:1292-1301.

7. Van Cutsem E, Peeters M, Siena S, Humblet $Y$, Hendlisz A, Neyns B, et al. Open-label phase III trial of panitumumab plus best supportive care compared with best supportive care alone in patients with chemotherapy-refractory metastatic colorectal cancer. J Clin Oncol 2007;25:1658-64.

8. Siena S, Peeters M, Van C, Humblet Y, Conte P, Bajetta E, et al. Association of progressionfree survival with patient-reported outcomes and survival: results from a randomised phase 3 trial of panitumumab. Br | Cancer 2007:97:1469-74.

9. Van Cutsem E, Siena S, Humblet Y, Canon JL, Maurel J, Bajetta E, et al. An open-label, single-arm study assessing safety and efficacy of panitumumab in patients with metastatic colorectal cancer refractory to standard chemotherapy. Ann Oncol 2008;19:92-8.

10. Amado RG, Wolf M, Peeters M, Van Cutsem E, Siena S, Freeman D, et al Wild-Type KRAS is required for panitumumab efficacy in patients with metastatic colorectal cancer. | Clin Oncol 2008;26:1626-34.

11. Peeters M, Siena S, Van Cutsem E, Sobrero A, Hendlisz A, Cascinu S, et al. Association of progression-free survival, overall survival, and patient-reported outcomes by skin toxicity and KRAS status in patients receiving panitumumab monotherapy. Cancer 2009;115:1544-54

12. Peeters M, Oliner KS, Parker A, Siena S, Van Cutsem E, Huang I et al. Massively parallel tumour multigene sequencing to evaluate response to embolism, acute renal failure and neurological toxicity.

\section{SUMMARY OF EVIDENCE:}

In patients with metastatic colorectal cancer and wild-type KRAS, the addition of panitumumab to the first-line chemotherapy regimen (FOLFOX-4) added 1.6 months to the progression-free survival, but did not show improvement in overall survival. When associated with a second-line chemotherapy regimen (monotherapy or FOLFIRI) in patients with good performance status and adequate organic function, it added 1 to 2 months in progression-free survival without showing a favourable result with an increase in overall survival.

The results of the studies were affected by crossover and sequential treatments. There are also important biases found in the critical analysis of studies such as subgroup analysis and lack of independent evaluator for data analysis.

panitumumab in a randomized phase III study of metastatic colorectal cancer. Clin Cancer Res 2013 1; 19(7):1902-12.

13. Giusti RM, Shastri KA, Cohen MH, Keegan P, Pazdur R. FDA drug approval summary: panitumumab (Vectibix). Oncologist 2007;12(5):577-83.

14. Douillard JY, Siena S, Cassidy J, Tabernero J, Burkes R, Barugel M et al. Randomized, phase III trial of panitumumab with infusional fluorouracil, leucovorin, and oxaliplatin (FOLFOX4) versus FOLFOX4 alone as first-line treatment in patients with previously untreated metastatic colorectal cancer: the PRIME study. J Clin Oncol 2010 1;28(31):4697-705.

15. Douillard IY, Oliner KS, Siena S, Tabernero I, Burkes R, Barugel M et al. Panitumumab-FOLFOX4 treatment and RAS mutations in colorectal cancer. N Engl | Med. 2013 Sep 12;369(11):1023-34.

16. Peeters M, Price TJ, Cervantes A, Sobrero AF, Ducreux M, Hotko $Y$ et al. Randomized phase III study of panitumumab with fluorouracil, leucovorin, and irinotecan (FOLFIRI) compared with FOLFIRI alone as second-line treatment in patients with metastatic colorectal cancer. J Clin Oncol 2010 1; 28(31):4706-13.

17. Peeters M, Price T), Cervantes A, Sobrero AF, Ducreux M, Hotko $Y$ et al. Final results from a randomized phase 3 study of FOLFIRI $\{+/-\}$ panitumumab for second-line treatment of metastatic colorectal cancer. Ann Oncol 2014; 25(1): 107-16.

18. Hecht JR, Mitchell E, Chidiac T, Scroggin C, Hagenstad C, Spigel D et al. A randomized phase IIIB trial of chemotherapy, bevacizumab, and panitumumab compared with chemotherapy and bevacizumab alone for metastatic colorectal cancer. J Clin Oncol 2009 10; 27(5):672-80.

19. Jadad AR, Moore RA, Carroll D, Jenkinson C, Reynolds DJ, Gavaghan DJ, et al. Assessing the quality of reports of randomized clinical trials: is blinding necessary? Control Clin Trials 1996; 17:1-12.

20. Goldet G, Howick |. Understanding GRADE: an introduction. | Evid Based Med 2013: 6:50-4.

21. Wells $G$, Shea $B$, O'Connell D, Robertson I, Peterson I, Welch $V$, et al. The Newcastle-Ottawa Scale (NOS) for assessing the quality of nonrandomised studies in meta-analyses. Disponível em: http://www.ohri.ca/ programs/clinical_epidemiology/oxford.asp.

22. Levels of Evidence and Grades of Recommendations - Oxford Centre for Evidence Based Medicine. Disponível em URL: http://cebm.jr2.ox.ac.uk/ docs/old_levels.htm. 


\section{ANNEX I}

\section{Clinical Question}

Do patients with metastatic colorectal cancer benefit from the use of panitumumab?

\section{Structured Question}

\begin{tabular}{l|l}
\hline $\mathbf{P}$ & Patients with metastatic colorectal cancer \\
\hline $\mathbf{I}$ & Chemotherapy with panitumumab \\
\hline $\mathbf{C}$ & $\begin{array}{l}\text { Chemotherapy without panitumumab or placebo or } \\
\text { supportive care }\end{array}$ \\
\hline $\mathbf{O}$ & Survival and adverse events (efficacy and safety)
\end{tabular}

\section{Evidence-Seeking Strategy}

\subsection{PubMed-Medline}

\#1 - Colorectal Neoplasms

\#2 - (Antibodies, Monoclonal OR panitumumab)

\#3 - Random*

$1^{\text {st }}$ RECOVERY $=\# 1$ AND \#2 AND \#3 = 595

(Colorectal Neoplasms AND (Antibodies, Monoclonal OR panitumumab) AND Random*)

\subsection{Cochrane/Lilacs/BVS}

\#1 - Colorectal Neoplasms
\#2 - Antibodies, Monoclonal

$2^{\text {nd }}$ RECOVERY $=\# 1$ AND \#2 $=210$

(Colorectal Neoplasms AND Antibodies, Monoclonal)

\section{Papers Recovered}

Obtaining the evidence to be used followed the steps of preparation of the clinical question, structuring the question, search for evidence, critical evaluation and selection of evidence, exposure of results and recommendations.

The bases of scientific information consulted were Medline via PubMed and Cochrane/Lilacs/BVS. Manual search from references of reviews (narratives or systematic), as well as the selected papers, was performed.

595 recovered papers were recovered until the last search date with the final search strategy.

\section{Criteria for inclusion of selected papers}

The selection of the studies, evaluation of titles and abstracts obtained with the search strategy in the consulted information bases was carried out by two researchers with skills in the preparation of systematized reviews, independently and blindly, strictly following the inclusion and exclusion criteria estab- lished and described in the PICO components, finally separating the papers with potential relevance.

All the papers recovered in the primary and secondary information bases were evaluated. In the primary bases, after the first critical evaluation, we selected PubMed-Medline (12) and Cochrane/Lilacs/ BVS (zero). In the manual search, no papers were selected.

\subsection{According to the study designs}

Only studies with a Randomized Clinical Trial (phase III) study design were included. When the clinical question was considered relevant, the protocol of this review allowed to broaden the search criteria including some evidence with subgroup analysis.

\subsection{Language}

Studies available in Portuguese, English or Spanish were included.

\subsection{According to the publication}

Only papers whose complete texts were available were considered for critical evaluation.

\section{Method of critical evaluation}

The papers considered for full text reading were critically evaluated according to the inclusion and exclusion criteria, by Study design, PICO, language and availability of the full text.

Of 12 papers considered for critical evaluation, none were excluded due to the lack of full text.

The papers included in the evaluation are from between 2007 and 2014.

When, after applying the inclusion and exclusion criteria, the selected evidence was defined as a ran-

TABLE 1 - CRITICAL EVALUATION SCRIPT FOR RANDOMIZED CONTROLLED TRIALS

\begin{tabular}{l|l}
\hline $\begin{array}{l}\text { Study date } \\
\text { Reference, Study design, JADAD, } \\
\text { evidence strength }\end{array}$ & $\begin{array}{l}\text { Sample calculation } \\
\text { Estimated differences, power, } \\
\text { significance level, total patients }\end{array}$ \\
\hline $\begin{array}{l}\text { Patient selection } \\
\text { Inclusion and exclusion criteria }\end{array}$ & $\begin{array}{l}\text { Patients } \\
\text { Recruited, randomized, prognostic } \\
\text { differences }\end{array}$ \\
\hline $\begin{array}{l}\text { Randomization } \\
\text { Description and blind allocation }\end{array}$ & $\begin{array}{l}\text { Patients follow-up } \\
\text { Time, losses, migration }\end{array}$ \\
\hline $\begin{array}{l}\text { Treatment protocol } \\
\text { Intervention, control and blinding }\end{array}$ & $\begin{array}{l}\text { Analysis } \\
\text { Treatment intention, analysed, } \\
\text { intervention and control }\end{array}$ \\
\hline $\begin{array}{l}\text { Considered outcomes } \\
\text { Main, secondary, measurement in- } \\
\text { strument of the outcome of interest }\end{array}$ & $\begin{array}{l}\text { Result } \\
\text { Benefit or harm in absolute data, } \\
\text { average benefit or harm }\end{array}$ \\
\hline
\end{tabular}


TABLE 2 - CRITICAL EVALUATION SCRIPT OF COHORT STUDIES

\begin{tabular}{|c|c|c|c|c|c|c|}
\hline $\begin{array}{l}\text { Representative- } \\
\text { ness of exposed } \\
\text { and selection of } \\
\text { non-exposed } \\
\text { (max. } 2 \text { points) }\end{array}$ & $\begin{array}{l}\text { Definition of } \\
\text { exposure } \\
\text { (max. } 1 \text { point) }\end{array}$ & $\begin{array}{l}\text { Demonstration } \\
\text { that the outcome } \\
\text { of interest was } \\
\text { not present at the } \\
\text { beginning of the } \\
\text { study } \\
\text { (max. } 1 \text { point) }\end{array}$ & $\begin{array}{l}\text { Comparability on } \\
\text { the basis of design } \\
\text { or analysis } \\
\text { (max. } 2 \text { points) }\end{array}$ & $\begin{array}{l}\text { Evaluation of } \\
\text { outcome } \\
\text { (max. } 1 \text { point) }\end{array}$ & $\begin{array}{l}\text { Follow-up appro- } \\
\text { priate time } \\
\text { (max. } 2 \text { points) }\end{array}$ & $\begin{array}{l}\text { Evidence level } \\
\text { score }\end{array}$ \\
\hline
\end{tabular}

domized controlled trial (RCT), it underwent an appropriate critical evaluation checklist (Table 1). The critical evaluation of the RCT allows classification according to the JADAD score ${ }^{19}$, considering the JADAD tests $<$ three (3) as inconsistent (grade B), and those with score $\geq$ three (3), consistent (grade A), and according to the GRADE $\operatorname{score}^{20}$ (strong or moderate evidence).

When the selected evidence was defined as a comparative study (observational cohorts or non-randomized clinical trial), it was submitted to an appropriate critical evaluation checklist (Table 2), allowing the classification of the study according to the NEWCASTLE OTTAWA SCALE score ${ }^{21}$, considering cohort studies with score $\geq 6$ consistent, and $<6$ inconsistent.

\section{Exposure of results}

For results with available evidence, the population, intervention, outcomes, presence or absence of benefit and/or harm and controversies will be specifically defined, whenever possible.

The results will be preferentially exposed in absolute data, absolute risk, number needed to treat
(NNT), or number needed to harm (NNH), and possibly in average and standard deviation (table 3 ).

TABLE 3 - WORKSHEET USED TO DESCRIBE AND EXPOSE THE RESULTS OF EACH STUDY

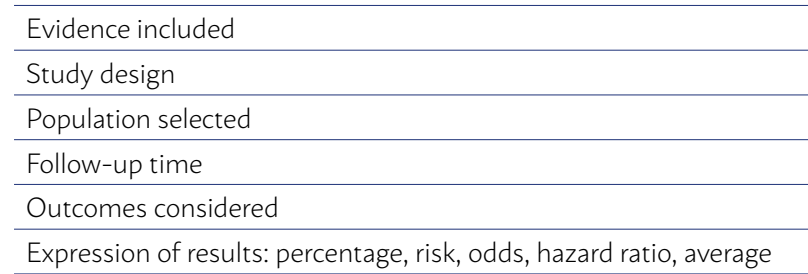

\section{Recommendations}

The recommendations will be prepared by the authors of the review, with the initial characteristic of the evidence synthesis being submitted to the validation by all authors participating in the preparation of the Guideline.

The degree of recommendation to be used comes directly from the available strength of the studies included according to $\mathrm{Oxford}^{22}$, and the use of the GRADE $^{20}$ system. 